\title{
Upaya Peningkatan Status Kesehatan Pada Ibu dan Bayi Melalui Program Katukisasi dan Widasi Di Puskesmas Mojosari Kecamatan Mojosari Kabupaten Mojokerto
}

\author{
Dyah Siwi Hety ${ }^{1 *}$, Ika Yuni Susanti² \\ ${ }^{1,2}$,Sekolah Tinggi Ilmu Kesehatan Majapahit, Indonesia \\ dyahsiwi11@gmail.com
}

\begin{abstract}
ABSTRAK
WHO (World Health Organization) merekomendasikan para ibu untuk menyusui secara ekslusif selama 6 bulan, melanjutkannya dengan memberikan makanan pendamping ASI dari bahan-bahan lokal yang kaya nutrisi sambil tetap memberikan ASI sampai anak berusia 2 tahun atau lebih. Tujuan Pengabmas adalah Meningkatkan pengetahuan ibu hamil agar memahami tentang manfaat daun katuk dan ASI eksklusif di Puskesmas Mojosari Kabupaten Mojokerto.

Pertemuan kelas ibu dilakukan 4 kali pertemuan pada ibu hamil trimester III yaitu pemberian materi tentang Katukisasi dan Widasi, setelah pemberian materi di lanjutkan dengan penyerahan bibit pohon katuk. Evaluasi dilakukan sebanyak kurang lebih 5 sampai 6 kali untuk melihat kesesuaian dengan hasil kesepakatan fasilitator dengan peserta. Pada setiap pertemuan, materi kelas ibu yang akan disampaikan adalah tentang manfaat daun katuk bagi ibu hamil dan ibu meneteki, dan dilanjutkan dengan manfaat ASI Eksklusif. Pada setiap akhir pertemuan dilakukan tanya jawab tentang materi yang telah diberikan. Kegiatan ini merupakan pemberian materi dan pemberian pohon katuk bagi ibu hamil trimester III, setelah sampai di rumah diharapkan dapat dipelajari, dipahami dan penanaman bibit pohon katuk. Waktu pertemuan disesuaikan dengan jadwal ANC terpadu di Puskesmas Mojosari, yaitu setiap hari selasa dan rabu.

Keberhasilan dari program ini di harapkan Ibu hamil dan ibu meneteki secara bersamasama terus dan selalu berdiskusi, tukar pendapat, tukar pengalaman akan pemenuhan pelayanan kesehatan khususnya tentang manfaat daun katuk dan ASI eksklusif dibimbing oleh fasilitator.
\end{abstract}

Kata Kunci: Lansia, Dimensia, Mini Mental State Examination

Received: October, 19, 2019

Revised: December 12, 2019

Accepted: February 11, 2020

\section{(i) (2)}

This is an open-acces article distributed under the terms of the Creative Commons Attribution-ShareAlike 4.0 International License.

\section{PENDAHULUAN}

Setiap bayi berhak mendapatkan air susu ibu eksklusif sejak dilahirkan selama 6 (enam) bulan, kecuali atas indikasi medis. Selama pemberian air susu ibu, pihak keluarga, Pemerintah, pemerintah daerah, dan masyarakat harus mendukung ibu bayi secara penuh dengan penyediaan waktu dan fasilitas khusus (UU Kesehatan no 36 /2009 pasal 128). 
WHO (World Health Organization) merekomendasikan para ibu untuk menyusui secara ekslusif selama 6 bulan, melanjutkannya dengan memberikan makanan pendamping ASI dari bahan - bahan lokal yang kaya nutrisi sambil tetap memberikan ASI sampai anak berusia 2 tahun atau lebih (World Health Assembely Resolution, 2010). Data WHO tahun 2016 menyebutkan hanya $42 \%$ bayi mendapatkan ASI eksklusif pada 6 bulan pertama kehidupannya dan $55 \%$ pada bayi usia kurang dari 2 tahun. Data profil kesehatan Indonesia tahun 2016, persentase pemberian ASI eksklusif pada bayi usia 0-6 bulan di Indonesia pada tahun 2016 sebesar 42\%. (Kemenkes RI, 2016). Profil Kesehatan Propinsi Jawa Timur tahun 2015, cakupan ASI eksklusi sebesar 73,8\%, sedangkan cakupan ASI eksklusif di Kabupaten Mojokerto yaitu sebesar 51,7\% (Dinkes Jatim, 2015).

Setiap ibu berkewajiban memberikan air susu ibu kepada anaknya untuk mencapai pertumbuh dan perkembangn secara optimal baik fisik, mental, spiritual maupun kecerdasan untuk mewujudkan kehidupan terbaik. bagi anak. 80\% (delapan puluh persen) perkembangan oleh anak dimulai sejak dalam kandungan sampai usia 3 (tiga) tahun (periode emas), sehingga diperlukan pemberian air susu ibu eksklusif 6 (enam) bulan diteruskan sampai anak berusia 2 (dua) tahun. Dalam memberikan ASI seorang ibu perlu mendapatkan dukungan dari keluarga (suami, ibu, mertua) dan lingkungan sosial, lingkungan tempat. Untuk mewujudkan hal tersebut maka kami melakukan kemitraan bersama Puskesmas Mojosari membuat suatu inovasi tentang Katukisasi dan Widasi. Jadi setiap ibu hamil trimester III diberi hadiah pohon katuk untuk di budidayakan sebagai persiapan pemenuhan gizi pada masa meneteki. Setelah itu ibu wajib meneteki sampai usia 6 bulan atau kita sebut dengan ASI Eksklusif. Bagi ibu - ibu yang selesai meneteki sampai usia 6 bulan, nantinya akan di beri suatu penghargaan yaitu WIDASI (Wisuda ASI Eksklusif).

Puskesmas Mojosari Kecamatan Mojosari Kabupaten Mojokerto terdiri dari 9 wilayah, yaitu: Desa Awang-awang, desa Belahan Tengah, desa Sumbertanggul, desa Randubangu, desa Seduri, kelurahan Kauman, kelurahan Sarirejo, kelurahan Sawahan dan kelurahan Mojosari. Sebagai mitra kami nanti adalah ibu hamil trimester III di wilayah Puskesmas Mojosari. Kegiatan pendidikan dan pelatihan ini dilakukan dengan membentuk kelompok kelas ibu hamil perdesa. Kegiatan kelas ibu hamil bertujuan untuk memberikan pengalaman dan pengetahuan kepada ibu yang sedang hamil tentang permasalahan yang biasanya terjadi pada masa kehamilan masa nifas. Kegiatan tersebut juga untuk meningkatkan cakupan ASI Eksklusif dan interaksi antar ibu hamil agar mereka dapat bertukar pikiran dan pengalaman seputar peningkatan status kesehatan.

\section{METODE}

1. Survei Lapangan.

Survei lapangan bertujuan untuk mengamati situasi dan keadaan desa di wilayah Puskesmas, yang direncanakan sebagai objek sasaran.

2. Menentukan Sasaran

Sasaran program kelas ibu yaitu ibu hamil trimester III dan ibu meneteki di Wilayah Kerja Puskesmas Mojosari Kecamatan Mojosari Kabupaten Mojokerto.

3. Koordinasi

Berkoordinasi dengan pihak Puskesmas Mojosari, untuk menentukan kesepakatan mufakat antara pelaksana program dengan masyarakat.

4. Sosialisasi Program

Sosialisasi program bertujuan untuk memberikan informasi mengenai rencana serangkaian pelaksanaan program yang disampaikan kepada kader, bidan, dan kepala 
desa seluruh Wilayah Kerja Puskesmas Mojosari.

\section{Pelaksanaan Program}

Pertemuan kelas ibu dilakukan 4 kali pertemuan pada ibu hamil trimester III yaitu pemberian materi tentang Katukisasi dan Widasi, setelah pemberian materi di lanjutkan dengan penyerahan bibit pohon katuk. Evaluasi dilakukan sebanyak kurang lebih 5 sampai 6 kali untuk melihat kesesuaian dengan hasil kesepakatan fasilitator dengan peserta. Pada setiap pertemuan, materi kelas ibu yang akan disampaikan adalah tentang manfaat daun katuk bagi ibu hamil dan ibu meneteki, dan dilanjutkan dengan manfaat ASI Eksklusif. Pada setiap akhir pertemuan dilakukan tanya jawab tentang materi yang telah diberikan. Kegiatan ini merupakan pemberian materi dan pemberian pohon katuk bagi ibu hamil trimester III, setelah sampai di rumah diharapkan dapat dipelajari, dipahami dan penanaman bibit pohon katuk. Waktu pertemuan disesuaikan dengan jadwal ANC terpadu di Puskesmas Mojosari, yaitu setiap hari selasa dan rabu.

\section{HASIL}

Pelaksanaan kegiatan ini dimulai dengan melakukan persiapan penyusunan proposal kemudian menyusun materi dan berkoordinasi dengan Bidan penanggung jawab untuk menyesuaikan dengan kegiatan ibu hamil. Jumlah peserta dalam kegiatan ini kurang lebih 60 ibu hamil.

Kegiatan ini secara garis besar menunjukkan hal yang menggembirakan yaitu hampir $100 \%$ peserta merespon positif dalam hal kemanfatan yang sangat tinggi.

\section{PEMBAHASAN}

Para mitra sebagian adalah ibu-ibu yang bekerja baik di pemerintah, wiraswasta dan sebagian besar adalah pekerja pabrik. Baik di perusahaan atau pabrik-pabrik serta home industri. Dampak dari keadaan tersebut adalah banyak bayi yang diasuh oleh neneknya atau saudaranya, dan tidak sempat memberikan ASI secara ekslusif serta kurangnya asupan nutrisi pada masa meneteki.

Dukungan suami masih kurang, dikarenakan tingkat pendidikan rendah dan sibuk bekerja. Dukungan suami serta keluarga mempunyai peran yang besar dalam memberikan perasaan yang nyaman dan merasa di cintai oleh suami dan keluarga.

Dalam kegiatan 60 orang ibu hamil ibu meneteki di Puskesmas Mojosari. Kegiatan dibagi dalam 2 sesi yakni, sesi pemaparan materi dan dilanjutkan dengan sesi tanya jawab. Dari sesi tanya jawab yang dilakukan bersama bidan, peserta cukup antusias, yang ditunjukkan dengan banyaknya yang bertanya. Dalam evaluasi kegiatan : Kegiatan berjalan dengan lancar, peserta mengikuti kegiatan dengan tertib. Dari kegiatan tersebut peserta dapat mengetahui tentang manfaat daun katuk dan ASI eksklusif

\section{KESIMPULAN}

Keberhasilan dari program ini di harapkan Ibu hamil dan ibu meneteki secara bersamasama terus dan selalu berdiskusi, tukar pendapat, tukar pengalaman akan pemenuhan pelayanan kesehatan khususnya tentang manfaat daun katuk dan ASI eksklusif dibimbing oleh fasilitator

\section{UCAPAN TERIMAKASIH}

Ucapan terimakasih kami sampaikan kepada segenap pihak yang membantu pelaksanaan kegiatan pengabdian kepada masyarakat ini antara lain kepada para mitra, phak puskesmas dan ibu-ibu yang berpartisipasi dalam kegiatan ini. 


\section{DAFTAR PUSTAKA}

Pusat pendidikan tenaga kesehatan departemen kesehatan RI, 2013, Asuhan Keperawatan Anak Dalam Konteks Keluarga, Cetakan kedua. Jakarta.

Perawatan Anak Dari Pusat Kesehatan Masyarakat

Ilmu Kesehatan Anak 1, 2015, Sistem Imunisasi dan penyakit imun Prof. Dr. Samik Wahab A, Dr. Madarina Juba MPH, 2012

http://istanatern.blogspot.co.id/2015/07/bahaya-daun-katuk-untuk-ibu-hamil-dan.html http://disehat.com/manfaat-daun-katuk-untuk-kesehatan-ibu-hamil-dan-menyusui/ https://www.ibudanbalita.com/artikel/4-manfaat-daun-katuk-untuk-ibu-menyusui https://www.khasiatmanfaatdaun.com/2017/11/manfaat-daun-katuk-untuk-ibu-hamil-danmenyusui.html https://sovianchoeruman.wordpress.com/2010/08/30/daun-katuk-ada-manfaat-danbahanyal

https://www.google.co.id/amp/s/aziezahfarmasist.wordpress.com/2011/12/08/makalahtenatng-daun-katuk/amp/ 